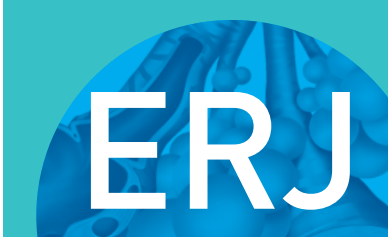

open research

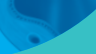

\title{
Trends and risk factors for death and excess all-cause mortality among notified tuberculosis patients in the UK: an analysis of surveillance data
}

\author{
Debora Pedrazzoli ${ }^{1,5}$, Katharina Kranzer ${ }^{2,5}$, H. Lucy Thomas ${ }^{3}$ and \\ Maeve K. Lalor 3,4
}

Affiliations: 'Dept of Infectious Disease Epidemiology, London School of Hygiene and Tropical Medicine, London, UK. ${ }^{2}$ Dept of Clinical Research, London School of Hygiene and Tropical Medicine, London, UK. ${ }^{3}$ TB Unit, Tuberculosis, Acute Respiratory, Gastrointestinal, Emerging/Zoonotic Infections and Travel Migrant Health Division (TARGETS), National Infection Service, Public Health England, London, UK. ${ }^{4}$ Institute for Global Health, University College London, London, UK. ${ }^{5}$ These authors contributed equally to this work.

Correspondence: Debora Pedrazzoli, Dept of Infectious Disease Epidemiology, London School of Hygiene and Tropical Medicine, Keppel Street, London, WC1E 7HT, UK. E-mail: debora.pedrazzolialshtm.ac.uk

\section{ABSTRACT}

Introduction: In the UK, several hundred patients notified with tuberculosis (TB) die every year. The aim of this article is to describe trends in deaths among notified TB patients, explore risk factors associated with death and compare all-cause mortality in TB patients with age-specific mortality rates in the general UK population.

Methods: We used 2001-2014 data from UK national TB surveillance to explore trends and risk factors for death, and population mortality data to compare age-specific death rates among notified TB patients with annual death rates in the UK general population.

Results: The proportion of TB patients in the UK who died each year declined steadily from $7.1 \%$ in 2002 to $5.5 \%$ in 2014 . One in five patients $(21.3 \%)$ was diagnosed with TB post-mortem. Where information was available, almost half of the deaths occurred within 2 months of starting treatment. Risk factors for death included demographic, disease-specific and social risk factors. Age had by far the largest effect, with patients aged $\geqslant 80$ years having a 70 times increased risk of death compared with those aged $<15$ years. In contrast, excess mortality determined by incidence ratios comparing all-cause mortality among TB patients with that of the general population was highest among children and the working-age population (15-64 years old).

Conclusions: Efforts to control TB and improve diagnosis and treatment outcomes in the UK need to be sustained. Control efforts need to focus on socially deprived and vulnerable groups. There is a need for further in-depth analysis of deaths of TB patients in the UK to identify potentially preventable factors.

@ERSpublications

Despite an overall decline in death among TB patients in the UK, patients with TB are still 6 times more likely to die during follow-up than the annual death rate in the general population http://bit.ly/2MqDw9Q

Cite this article as: Pedrazzoli D, Kranzer K, Thomas HL, et al. Trends and risk factors for death and excess all-cause mortality among notified tuberculosis patients in the UK: an analysis of surveillance data. ERJ Open Res 2019; 5: 00125-2019 [https://doi.org/10.1183/23120541.00125-2019].

This article has supplementary material available from openres.ersjournals.com

Received: 20 May 2019 | Accepted after revision: 24 Sept 2019

Copyright $\odot$ ERS 2019. This article is open access and distributed under the terms of the Creative Commons Attribution Non-Commercial Licence 4.0. 


\section{Introduction}

The 2018 Global Tuberculosis (TB) Report published by the World Health Organization (WHO) estimated 10 million TB incident patients and 1.6 million TB-related deaths in 2017 [1]. While the majority of TB-related deaths occur in low-income countries, high all-cause mortality is also seen among TB patients in Western Europe. TB mortality rates have declined globally with an annualised rate of change of $-4.1 \%$ from 2005 to 2015 . Within the European Union, mortality rates declined even faster with an estimated annual percentage change of $-8.1 \%$ for females and $-7 \%$ for males between 2000 and 2010 [2]. However, to achieve the milestone for reduction in TB deaths set in the WHO's End TB Strategy, the global case fatality rate (CFR) needs to fall to $10 \%$ by 2020 and $6 \%$ by 2025 [1]. In high-income countries, socioeconomic status, noninfective comorbidities, sputum smear positivity and alcohol or substance abuse are all associated with higher mortality among TB patients [3-6].

The UK, like many other European countries, has seen a remarkable decline in TB notifications and mortality over the last 100 years [7]. However, in recent years the decline in mortality has been slower compared with the average TB mortality decline in the European Region between 2000 and $2010(-4.6 \%$ in the UK versus $-7 \%$ in the European Union) [2]. A possible explanation may be the concentration of the TB epidemic in major cities, among foreign-born residents, recent immigrants and certain groups of socially marginalised citizens [8].

In this article, using data from national TB surveillance, we describe trends in deaths, explore risk factors associated with death among notified TB patients in the UK and compare all-cause mortality in TB patients with overall age-specific mortality rates in the UK, in order to inform TB control strategies with an aim of reducing mortality in TB patients.

\section{Methods}

TB patients notified to national TB surveillance in the UK between January 1, 2001 and December 31, 2014 were included in this analysis. 2014 was the most recent year of notification to allow the TB patients included up to 24 months of follow-up.

In the UK, there is a statutory requirement to notify all TB patients, including patients that died prior to starting treatment or identified post-mortem [9]. TB patients in England, Wales and Northern Ireland are notified to the Public Health England Enhanced Tuberculosis Surveillance System; these data are compiled with patients notified to the Enhanced Surveillance of Mycobacterial Infections system in Scotland to create a complete UK dataset. Case data are matched to laboratory data on Mycobacterium tuberculosis complex isolates through a probabilistic record linkage (Enhanced Matching System) [10]. Demographic data (age, sex, UK/non-UK born, ethnic group) and clinical variables (site of disease, notification date, smear and culture results) were included. Data on social risk factors (i.e. current or history of homelessness, imprisonment or drug misuse and current alcohol misuse) were included from 2010, when these variables were being recorded for $>75 \%$ of patients.

Follow-up information is collected on outcomes for all TB patients at 12 months from the treatment start date or the notification date if the treatment start date is not reported. For patients still on treatment at 12 months (7.5\% of patients during the study period), follow-up is extended to 24 and 36 months as appropriate. The outcomes are recorded as "treatment completed", "died", "lost to follow-up", "still on treatment", "stopped" or "not evaluated". Reporting of TB outcomes in the UK is proactively followed up by regional and national TB surveillance teams. For the outcome "died", additional information is collected on whether TB caused or contributed to death, or whether TB was incidental to death.

We obtained mid-year population estimates and total annual deaths stratified by 5-year age groups for England and Wales from the Office for National Statistics, for Northern Ireland from the Northern Ireland Statistics and Research Agency, and for Scotland from the National Records of Scotland. We used these data to compare all-cause mortality rates among notified TB patients during their follow-up period with annual mortality rates in the UK general population.

\section{Analyses}

We used descriptive statistics to describe trends in the number and proportion of deaths among notified TB patients. The proportion of deaths among notified TB patients is not the same as the CFR, which is defined as the proportion of TB patients dying due to TB. We analysed all deaths in TB patients, rather than only deaths reported as caused by TB, as data were missing on whether TB caused, contributed to or was incidental to death for $43 \%$ of patients during the study period. In addition, there is a poor correlation between cause of death information in the TB surveillance system and in the vital registration system [11], suggesting that cause of death is not accurately reported. 
We performed univariable analyses to identify the characteristics of TB patients who died. We performed univariable logistic regression to identify risk factors associated with death. We conducted multivariable logistic regression using all factors from the univariable analyses to calculate adjusted odds ratios (aORs).

We repeated the analysis on a subset of data for the period 2010-2014 to investigate the association between social risk factors and death among TB patients. We conducted this analysis to ascertain any difference between patients that have at least one social risk factor recorded and those that do not have any social risk factor recorded (supplementary table S1).

Finally, we calculated incidence risk ratios (IRRs) to compare the risk of death among TB patients with the annual risk of death in the general UK population, stratified by age groups for the same period of analysis (2001-2014). We performed the analyses using Stata version 13.1 (StataCorp, College Station, TX, USA).

\section{Ethics statement}

Public Health England has authority to hold and analyse national surveillance data for public health and research purposes under the Health and Social Care Act 2012.

\section{Results}

Between January 1, 2001 and December 31, 2014, a total of 111991 TB patients were notified in the UK. Outcomes were recorded for 92.6\% (103727) of patients. 78.9\% (88352) completed treatment, 4.7\% (5251) were lost to follow-up, $2.1 \%$ (2366) were still on treatment and $1.1 \%(1218)$ had their treatment stopped by the last reported outcome. 5.8\% (6540) of TB patients died during the follow-up period after notification. TB caused or contributed to $34.7 \%$ (2269) of deaths, was incidental to $22.3 \%$ (1457) of deaths, and the relationship between TB and death was unknown for 43.0\% (2814) of deaths. Among those who died, $21.4 \%$ (1398 out of 6540) were diagnosed post-mortem and no treatment for TB was started. Of the remaining deaths, $55.2 \%$ ( 2840 out of 5142 ) had information on the time between starting treatment and death. The median (interquartile range) time to death after starting treatment was 38 (12-97) days; 61.7\% (1752) died within 2 months, 19.0\% (539) died between 2 and 4 months, 8.4\% (237) died between 4 and 6 months, and $11.0 \%$ died after at least 6 months of treatment.

The proportion of TB patients who had died at last reported outcome decreased from $6.8 \%$ (462 deaths) in 2001 to its lowest in 2013 (4.9\%; 387 deaths) before increasing slightly in 2014 to 5.5\% (389 deaths) (test for linear $\mathrm{p}<0.01$ ) (figure 1). All-cause mortality rates among TB patients decreased from 0.78 per 100000 population in 2001 to 0.60 per 100000 population in 2014 .

With the exception of children $<5$ years of age (among whom $1.2 \%$ died), the proportion of TB patients who died increased with increasing age, from $0.3 \%$ in those aged 5-9 years to $19 \%$ in those aged $65-79$ years and $38 \%$ among those aged $\geqslant 80$ years (table 1 and figure 2 ).

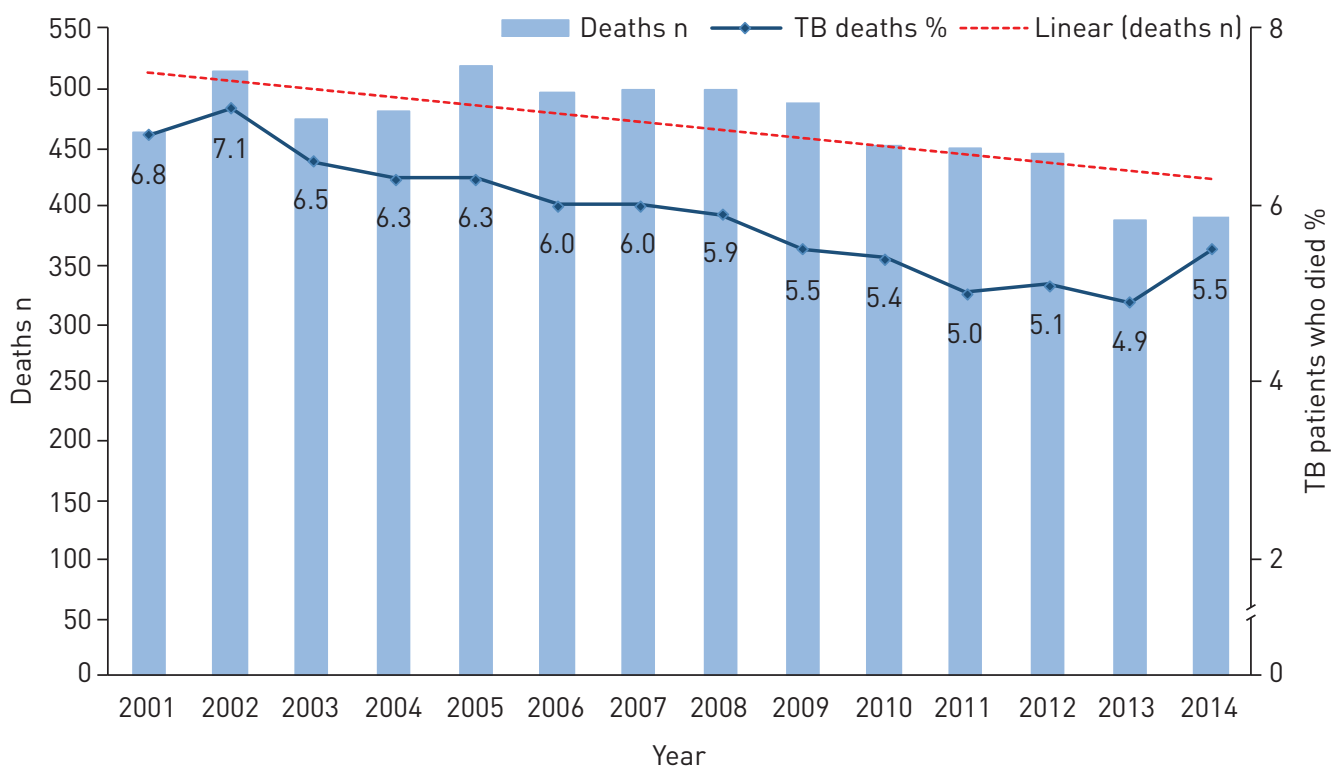

FIGURE 1 Number of deaths and percentage that died among tuberculosis (TB) patients in the UK, 2001-2014. 


\begin{tabular}{|c|c|c|c|c|}
\hline & $\begin{array}{c}\text { TB } \\
\text { patients } n\end{array}$ & $\begin{array}{c}\text { Deaths } \\
\mathrm{n}(\%)\end{array}$ & $\begin{array}{c}\text { Univariable analysis } \\
\text { OR }(95 \% \mathrm{CI})\end{array}$ & $\begin{array}{l}\text { Multivariate analysis } \\
\text { aOR }(95 \% \mathrm{CI})\end{array}$ \\
\hline Overall & 111991 & $6540(5.8)$ & & \\
\hline \multicolumn{5}{|l|}{ Sex } \\
\hline Male & 62628 & $4161(6.6)$ & $1.40(1.33-1.48)$ & $1.37(1.28-1.47)$ \\
\hline Female & 49146 & $2371(4.8)$ & 1.00 & 1.00 \\
\hline \multicolumn{5}{|l|}{ Age group years } \\
\hline $0-14$ & 5682 & $40(0.7)$ & 1.00 & 1.00 \\
\hline $15-44$ & 66863 & $903(1.4)$ & $1.93(1.41-2.65)$ & $1.87(1.29-2.71)$ \\
\hline $45-64$ & 22704 & $1516(6.7)$ & 10.09 (7.36-13.83) & $9.11(6.31-13.16)$ \\
\hline $65-79$ & 12094 & 2324 (19.2) & 33.55 (24.5-45.94) & 30.09 (20.84-43.44) \\
\hline$\geqslant 80$ & 4630 & $1757(38.0)$ & $86.26(62.85-118.39)$ & $70.80(48.84-102.63)$ \\
\hline \multicolumn{5}{|l|}{ Place of birth } \\
\hline UK & 30068 & $3062(10.2)$ & $3.21(3.04-3.39)$ & $1.35(1.19-1.54)$ \\
\hline Non-UK & 73902 & $2524(3.4)$ & 1.00 & 1.00 \\
\hline \multicolumn{5}{|l|}{ Ethnic group } \\
\hline White & 25650 & $3594(14.1)$ & $4.05(3.76-4.36)$ & $1.17(1.01-1.35)$ \\
\hline Black African & 21764 & $522(2.4)$ & $0.61(0.55-0.68)$ & $1.23(1.07-1.41)$ \\
\hline Indian & 24276 & 940 (3.9) & 1.00 & 1.00 \\
\hline Pakistani & 16827 & 657 (3.9) & $1.01(0.91-1.11)$ & $0.90(0.79-1.02)$ \\
\hline Bangladeshi & 3787 & 104 (2.8) & $0.70(0.57-0.86)$ & $0.95(0.74-1.22)$ \\
\hline Other & 15764 & $431(2.7)$ & $0.70(0.62-0.78)$ & $0.77(0.67-0.89)$ \\
\hline \multicolumn{5}{|l|}{ Site of disease } \\
\hline $\begin{array}{l}\text { Pulmonary sputum } \\
\text { smear-positive }\end{array}$ & 22526 & $1722(7.6)$ & 1.00 & 1.00 \\
\hline $\begin{array}{l}\text { Pulmonary sputum } \\
\text { smear-negative or } \\
\text { unknown }\end{array}$ & 39933 & $3262(8.2)$ & $1.07(1.01-1.14)$ & $0.91(0.83-0.98)$ \\
\hline Extrapulmonary & 49136 & $1531(3.1)$ & $0.39(0.36-0.42)$ & $0.46(0.42-0.51)$ \\
\hline \multicolumn{5}{|l|}{ Previous TB diagnosis } \\
\hline Yes & 7743 & $710(9.2)$ & $2.03(1.87-2.21)$ & $1.16(1.05-1.28)$ \\
\hline No & 88258 & $4181(4.7)$ & 1.00 & 1.00 \\
\hline \multicolumn{5}{|l|}{ MDR-TB } \\
\hline Yes & 806 & $47(5.8)$ & $0.96(0.71-1.28)$ & $2.40(1.66-3.48)$ \\
\hline No & 65304 & $3975(6.1)$ & 1.00 & 1.00 \\
\hline $\begin{array}{l}\text { Unknown (no culture } \\
\text { or DSTs) }\end{array}$ & 45881 & $2518(5.5)$ & $0.90(0.85-0.94)$ & $0.96(0.89-1.03)$ \\
\hline
\end{tabular}

aOR: adjusted OR; MDR: multidrug-resistant; DST: drug susceptibility test. Missing values: sex $\mathrm{n}=217$, age $n=12661$, place of birth $n=8021$, ethnic group $n=3923$, site of disease $n=396$, previous TB diagnosis $n=15990$ and MDR-TB $n=0$.

In the univariable analysis, TB patients who were male, born in the UK or of White ethnicity had the highest odds of death (table 1). In the fully adjusted model (table 1), older age was the factor most strongly associated with death, with those aged 65-79 years 30 times (OR 30.09, 95\% CI 20.84-43.44) more likely to die and with those aged $\geqslant 80$ years 70 times (OR 70.80, 95\% CI 48.84-102.63) more likely to die compared with children aged $0-14$ years. The other factors that remained significantly associated with death were multidrug-resistant (MDR)-TB (OR 2.40, 95\% CI 1.66-3.48), male sex (OR 1.40, 95\% CI 1.33-1.48), UK born of White or Black African ethnicity (OR 1.35, 95\% CI 1.19-1.54) and having had a previous TB diagnosis (OR 1.16, 95\% CI 1.05-1.28). Having only extrapulmonary disease was associated with decreased odds of death (OR 0.46, 95\% CI 0.42-0.51).

\section{Association between social risk factors and death}

Between 2010 and 2014, 40921 TB patients were notified, 81.7\% (33433) of whom had information on social risk factors. $10.1 \%$ (3207) were reported to have at least one social risk factor. Among the patients that died, $17 \%$ (230 out of 1365) had at least one social risk factor. The proportion of patients who died was higher among TB patients with any social risk factor (history of alcohol misuse/abuse, problem drug use, homelessness and imprisonment) compared with those without any social risk factors (7.2\% (230 out of 3726$)$ versus $3.8 \%$ (1135 out of 30226$)$ ). 


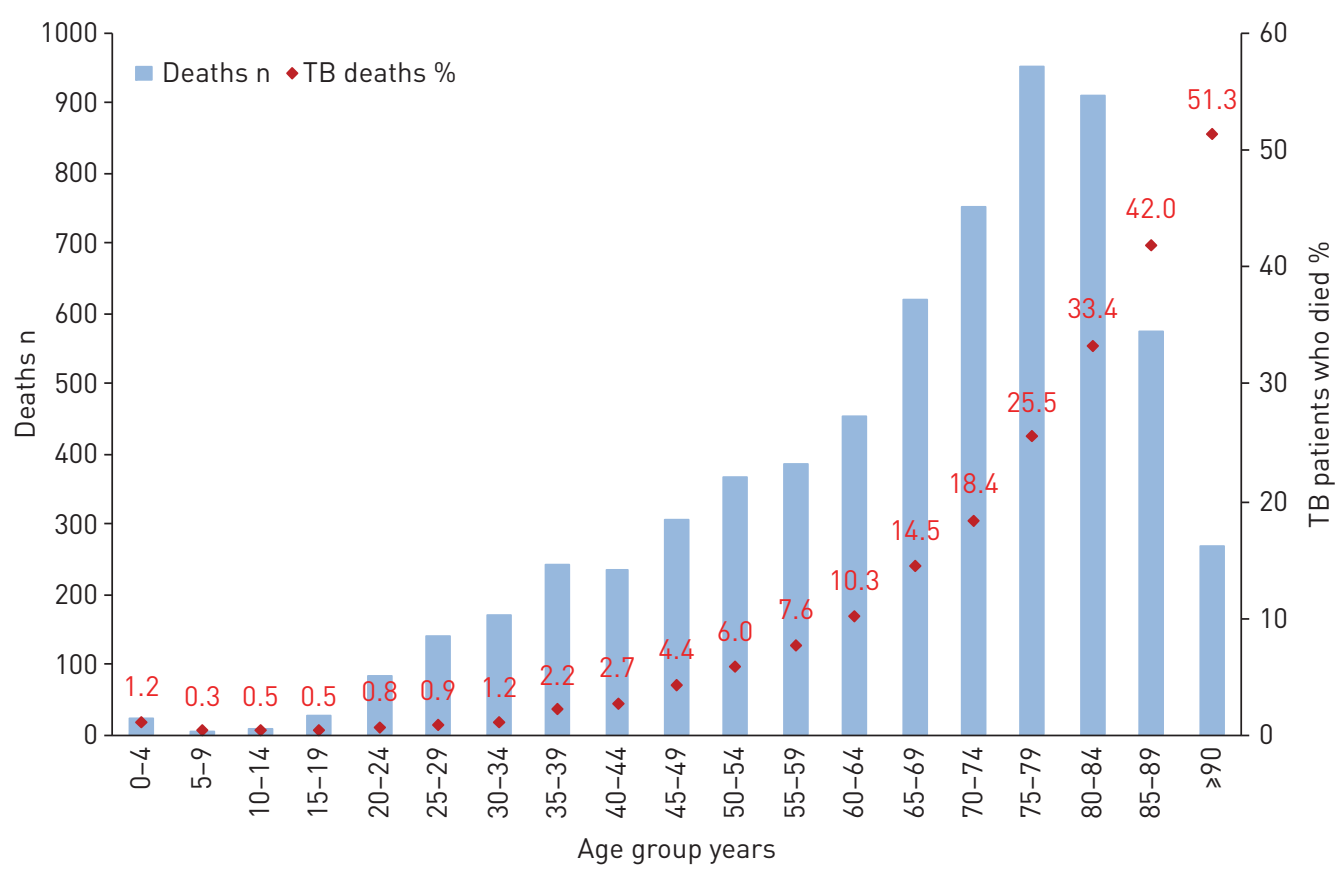

FIGURE 2 Number of deaths and percentage that died by age group among tuberculosis (TB) patients in the UK, 2001-2014.

In the multivariable analysis adjusted for age, sex, place of birth, ethnicity, site of disease and drug susceptibility, TB patients who died were 2.2 times more likely to have one or more social risk factors (table 2). MDR-TB (OR 2.47, 95\% CI 1.28-4.75), male sex (OR 1.29, 95\% CI 1.13-1.48) and increasing age remained associated with death, while White ethnicity and being born in the UK did not. Findings from this analysis showed that there was no significant difference between TB patients with available information on social risk factors and those with missing information (supplementary table S1).

\section{Comparing mortality among TB patients with mortality in the general UK population}

We found that all-cause mortality rates were significantly higher among notified TB patients than the UK general population across all age groups (figure 3). Overall, TB patients had a 6 times greater risk of death during their follow-up period compared with the annual risk of death in the general population (IRR 6.2, 95\% CI 6.1-6.4). IRRs were highest in those aged 5-9 years (IRR 46.7, 95\% CI 15.2-109.2) and 10-14 years (IRR 58.3, 95\% CI 29.1-104.4), although confidence intervals were very large due to the very small number of children and adolescents with TB who died. In the age group 15-54 years, IRRs were consistently $>20$ and decreased in older age groups, down to 3.6 in those aged $\geqslant 85$ years.

\section{Discussion}

This study shows that the proportion of TB patients in the UK who died declined steadily from $7.1 \%$ in 2002 to $5.5 \%$ in 2014. Of these deaths, $21.3 \%$ were diagnosed with TB post-mortem, and almost half (48.5\%) of those who started treatment and for whom information was available died within 2 months of starting treatment. Risk factors for death included demographic, disease-specific and social risk factors. Age had by far the largest effect, with TB patients aged $\geqslant 80$ years having a 70 times increased risk of death compared with those aged $<15$ years. In contrast, excess mortality determined by incidence ratios comparing all-cause mortality among TB patients with that of the general population was highest among children aged $\geqslant 5$ years followed by the working-age population (15-64 year olds).

Overall, $5.8 \%$ of TB patients in this cohort died, which compares favourably with other high-income countries in Europe, Canada and Israel [12-16], but higher than reported from low-income settings [17]. This likely reflects differences in the age structure of TB patients; in low-income settings TB mainly affects young individuals of working age, while in high-income settings a high proportion of TB patients are elderly $[12,14,18]$.

In this study, more than a fifth of TB patients who died were diagnosed with TB after they died. The number of post-mortem TB diagnoses greatly depends on autopsy rates in the country. These vary considerably across countries and have steadily declined over the past four decades [19-23]. The fact that 


\begin{tabular}{|c|c|c|c|c|}
\hline & $\begin{array}{c}\text { TB } \\
\text { patients } \mathrm{n}\end{array}$ & $\begin{array}{l}\text { Deaths } \\
\mathrm{n}(\%)\end{array}$ & $\begin{array}{c}\text { Univariable analysis } \\
\text { OR }(95 \% \mathrm{CI})\end{array}$ & $\begin{array}{c}\text { Multivariate analysis } \\
\text { aOR }(95 \% \mathrm{CI})\end{array}$ \\
\hline Overall & 40921 & $2117(5.2)$ & & \\
\hline \multicolumn{5}{|l|}{ Sex } \\
\hline Male & 23571 & 1384 (5.9) & $1.42(1.29-1.55)$ & $1.29(1.13-1.48)$ \\
\hline Female & 17279 & $729(4.2)$ & 1.00 & 1.00 \\
\hline \multicolumn{5}{|l|}{ Age group years } \\
\hline $0-14$ & 1793 & $10(0.6)$ & 1.00 & 1.00 \\
\hline $15-44$ & 24439 & $211(0.9)$ & $1.55(0.82-2.93)$ & $1.55(0.62-3.84)$ \\
\hline $45-64$ & 8876 & $522(5.9)$ & 11.14 (5.95-20.87) & $10.37(4.22-25.49)$ \\
\hline $65-79$ & 4123 & 753 (18.3) & 39.84 (21.29-74.54) & 42.35 (17.26-103.93) \\
\hline$\geqslant 80$ & 1690 & $621(36.8)$ & 103.58 (55.20-194.35) & 109.70 (44.5-270.38) \\
\hline \multicolumn{5}{|l|}{ Place of birth } \\
\hline UK & 28799 & 959 (8.9) & $2.96(2.40-3.25)$ & $1.21(0.96-1.53)$ \\
\hline Non-UK & 10732 & 923 (3.2) & 1.00 & 1.00 \\
\hline \multicolumn{5}{|l|}{ Ethnic group } \\
\hline White & 8778 & $1086(12.4)$ & $3.98(3.51-4.50)$ & $1.05(0.81-1.37)$ \\
\hline Black African & 6640 & $128(1.9)$ & $0.55(0.45-0.68)$ & $0.86(0.64-1.14)$ \\
\hline Indian & 10263 & 352 (3.4) & 1.00 & 1.00 \\
\hline Pakistani & 6599 & 259 (3.9) & $1.15(0.98-1.35)$ & $0.91(0.73-1.13)$ \\
\hline Bangladeshi & 1518 & $42(2.8)$ & $0.80(0.58-1.11)$ & $0.83(0.52-1.33)$ \\
\hline Other & 6167 & 155 (2.5) & $0.73(0.60-0.88)$ & $0.75(0.58-0.96)$ \\
\hline \multicolumn{5}{|l|}{ Site of disease } \\
\hline $\begin{array}{l}\text { Pulmonary sputum } \\
\text { smear-positive }\end{array}$ & 13592 & $1142(7.8)$ & 1.00 & 1.00 \\
\hline $\begin{array}{l}\text { Pulmonary sputum } \\
\text { smear-negative or } \\
\text { unknown }\end{array}$ & 6839 & $441(6.5)$ & $1.22(1.09-1.37)$ & $0.90(0.77-1.07)$ \\
\hline Extrapulmonary & 19185 & $523(2.7)$ & $0.41(0.36-0.46)$ & $0.47(0.38-0.57)$ \\
\hline \multicolumn{5}{|l|}{ Previous TB diagnosis } \\
\hline Yes & 2689 & 215 (8.0) & $2.04(1.76-2.37)$ & $1.20(0.98-1.47)$ \\
\hline No & 36040 & $1471(4.1)$ & 1.00 & 1.00 \\
\hline \multicolumn{5}{|l|}{ MDR-TB } \\
\hline Yes & 366 & $15(4.1)$ & $0.73(0.43-1.23)$ & $2.47(1.28-4.75)$ \\
\hline No & 24331 & $1346(5.5)$ & 1.00 & 1.00 \\
\hline $\begin{array}{l}\text { Unknown (no culture } \\
\text { or DSTs) }\end{array}$ & 16224 & $756(4.7)$ & $0.83(0.76-0.91)$ & $0.96(0.84-1.11)$ \\
\hline \multicolumn{5}{|l|}{ Social risk factors } \\
\hline$\geqslant 1$ & 3207 & $230(7.2)$ & $1.98(1.71-2.29)$ & $2.23(1.83-2.71)$ \\
\hline 0 & 30226 & $1135(3.8)$ & 1.00 & 1.00 \\
\hline
\end{tabular}

the majority of TB patients who had information on treatment start date and date of death died within 2 months of starting treatment, and that a large number of TB diagnoses were made post-mortem, suggests that earlier diagnosis may be key to reducing mortality. Studies from the UK and Spain have shown a considerable diagnostic delay between symptom onset, TB diagnosis and treatment initiation [24, 25]. The elderly may be particularly at risk of being diagnosed late due to atypical clinical presentations and chest radiography findings, which may be interpreted as changes related to older age [26-28].

Risk factors for death among TB patients in this study were older age, male sex, born in the UK, pulmonary TB, smear-positive disease, previous TB and MDR-TB. Other studies from low TB incidence settings have found similar associations $[12,14,15,29]$. In addition, our study found that having any social risk factor, such as current or history of homelessness, imprisonment or drug misuse and current alcohol misuse, doubled the risk of dying even after controlling for the demographic and disease-specific risk factors. Studies based on surveillance data rarely investigate the effect of social risk factors, as social risk factors are not routinely collected in many surveillance systems. However, previous studies using regional data have shown that current alcohol misuse and unemployment increase the risk of death among TB patients [30-33]. A recent study using data from 11 European countries showed substantial educational 


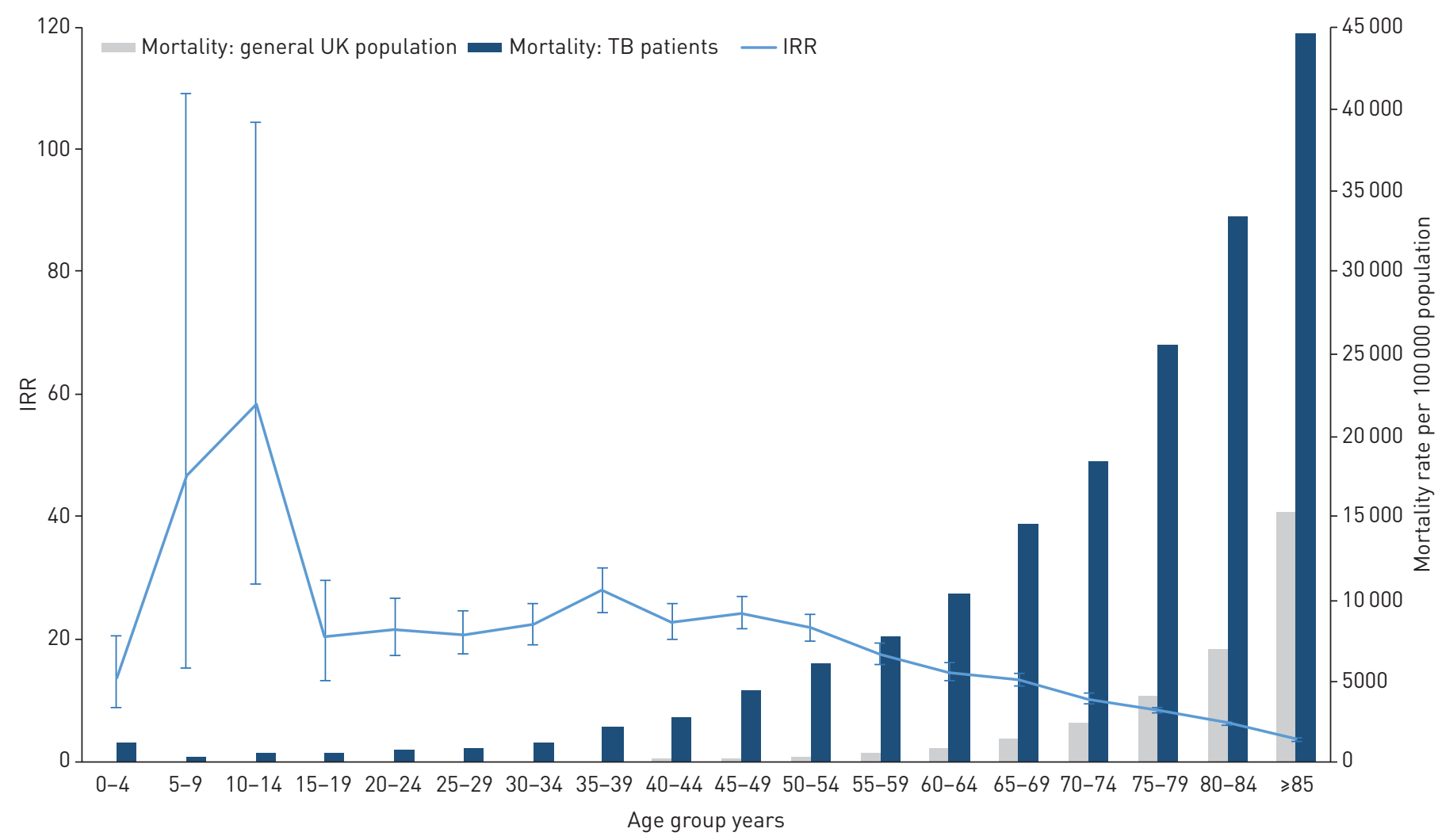

FIGURE 3 Mortality rates among tuberculosis (TB) patients and in the UK general population, and incidence rate ratios (IRRs), by age group, 2001-2014.

inequality in TB mortality, with higher death rates among those with lower educational levels compared with higher educational levels [34]. Taken together, these findings suggest that interventions aiming at earlier TB diagnosis and prompt initiation of treatment for socially deprived vulnerable groups are needed to decrease inequalities in TB mortality.

As would be expected, advancing age is the most prominent risk factor for all-cause mortality in TB patients. However, the association between age and death among TB patients does not accurately depict the true burden of excess mortality in TB patients. Comparison with the general population revealed a significant excess all-cause mortality in TB patients across all age groups, but particularly in children aged $\geqslant 5$ years followed by those aged 15-64 years. These results are in line with other studies from Taiwan, the Netherlands and Southern India [35-37].

This study has several important strengths. The study used data from a large national cohort with near-complete outcome reporting [11] and a high proportion of records with known date of death. Furthermore, the comparison with the general population allowed calculation of IRRs across age groups. To the best our knowledge, it is the first study of national surveillance data investigating the impact of social risk factors on death.

There are a few limitations to our study. Data on disease severity and comorbidities are not routinely captured by the surveillance system. Data on the relationship between TB and death were poorly completed in the surveillance system, so it was not possible to calculate the CFR. All-cause mortality rather than mortality due to TB was presented as the information on cause of death was often not recorded or may not have been accurately recorded as identified by comparing with information recorded in the UK's vital registration system [11]. An audit is planned to clarify why these differences occur and to inform development of clear guidance to improve reporting. In addition, TB/HIV co-infection data were not available and thus the impact of HIV could not be analysed. However, only $5 \%$ of TB patients were HIV-positive in the UK during the study period [38]. A considerable proportion of social risk factor data was missing during the study period; however, comparison of individuals with and without social risk factor information did not show any significant difference. Finally, in the comparison of mortality rates in TB patients with the general population it was not possible to control for any confounders apart from age. In addition, the follow-up period for the majority of TB patients was $<12$ months, so the comparison of 
the all-cause mortality in TB patients with annual mortality rates in the general population would have led to conservative estimates of the excess mortality in TB patients.

\section{Conclusions}

Despite an overall decline in death among TB patients in the UK during the study period, patients with TB are still 6 times more likely to die during follow-up than the annual death rate in the general population, and this excess mortality is particularly marked for children and working-age adults. While not all deaths in patients with TB are directly related to their TB disease, this high excess mortality clearly demonstrates the poor overall health and high vulnerability of the population with TB in the UK. The fact that TB patients generally die early in their course of TB treatment and a proportion are only diagnosed with TB post-mortem suggests that earlier diagnosis may be key to reducing TB-related mortality. The fact that TB patients with social risk factors are twice as likely to die as those without social risk factors suggests that efforts to reduce mortality need to specifically address the needs of socially deprived groups. This is particularly important given recent changes in TB epidemiology in the UK, with an increase in the proportion of patients with social risk factors as overall case numbers fall [39]. There is a need for further in-depth analysis of individual TB deaths to identify specific avoidable factors that can be addressed across the full pathway from health-seeking behaviour and access to services, through to diagnosis, treatment initiation and treatment completion.

Conflict of interest: None declared.

\section{References}

1 World Health Organization. Global Tuberculosis Report 2018. 2018. www.who.int/tb/publications/global_report/en Date last accessed: October 25, 2019.

2 Al-Rahamneh MJ, Al-Rahamneh A, Guillén-Grima F, et al. Mortality trends for tuberculosis in European Union countries, 2000-2010. Enferm Infecc Microbiol Clin 2018; 36: 342-351.

3 Marx FM, Fiebig L, Hauer B, et al. Higher rate of tuberculosis in second generation migrants compared to native residents in a metropolitan setting in Western Europe. PLoS One 2015; 10: e0119693.

4 Kodmon C, Zucs P, van der Werf MJ. Migration-related tuberculosis: epidemiology and characteristics of tuberculosis cases originating outside the European Union and European Economic Area, 2007 to 2013. Euro Surveill 2016; 21: 30164.

5 Walker TM, Lalor MK, Broda A, et al. Assessment of Mycobacterium tuberculosis transmission in Oxfordshire, UK, 2007-12, with whole pathogen genome sequences: an observational study. Lancet Respir Med 2014; 2: 285-292.

6 Story A, Murad S, Roberts W, et al. Tuberculosis in London: the importance of homelessness, problem drug use and prison. Thorax 2007; 62: 667-671.

7 Public Health England. Tuberculosis mortality and mortality rate, England and Wales, 1913-2013. 2013. www.gov. uk/government/publications/tuberculosis-tb-annual-notifications-1913-onwards Date last updated: July 25, 2019 Date last accessed: October 25, 2019.

8 Abubakar I, Lipman M, Anderson C, et al. Tuberculosis in the UK - time to regain control. BMJ 2011; 343 d4281.

9 Public Health England. Guidance on notifying tuberculosis (TB) cases. 2014. www.gov.uk/government/ publications/tuberculosis-notifying-cases Date last accessed: October 25, 2019.

10 Aldridge RW, Shaji K, Hayward AC, et al. Accuracy of probabilistic linkage using the Enhanced Matching System for public health and epidemiological studies. PLoS One 2015; 10: e0136179.

11 Lalor MK, Mohiyuddin T, Uddin T, et al. The challenge of estimating tuberculosis mortality accurately in England and Wales. Int J Tuberc Lung Dis 2018; 22: 572-578.

12 Lefebvre N, Falzon D. Risk factors for death among tuberculosis cases: analysis of European surveillance data. Eur Respir J 2008; 31: 1256-1260.

13 Vachon J, Gallant V, Siu W. Tuberculosis in Canada, 2016. Can Commun Dis Rep 2018; 44: 75-81.

14 Karo B, Hauer B, Hollo V, et al. Tuberculosis treatment outcome in the European Union and European Economic Area: an analysis of surveillance data from 2002-2011. Euro Surveill 2015; 2030087.

15 Shuldiner J, Leventhal A, Chemtob D, et al. Mortality of tuberculosis patients during treatment in Israel, 2000-2010. Int J Tuberc Lung Dis 2014; 18: 818-823.

16 European Centre for Disease Prevention and Control, World Health Organization Regional Office for Europe Tuberculosis surveillance and monitoring in Europe 2017. 2017. www.ecdc.europa.eu/sites/portal/files/media/en/ publications/Publications/ecdc-tuberculosis-surveillance-monitoring-Europe-2017.pdf Date last accessed: October 25, 2019.

17 Straetemans M, Glaziou P, Bierrenbach AL, et al. Assessing tuberculosis case fatality ratio: a meta-analysis. PLoS One 2011; 6: e20755.

18 Hauer B, Brodhun B, Altmann D, et al. Tuberculosis in the elderly in Germany. Eur Respir J 2011; 38: 467-470.

19 Blokker BM, Weustink AC, Hunink MGM, et al. Autopsy rates in the Netherlands: 35 years of decline. PLoS One 2017; 12: e0178200.

20 Rodewald AK, Bode P, Cathomas G, et al. Klinische Obduktionen in der Schweiz: Ein Statusbericht. [Clinical autopsies in Switzerland: a status report.] Pathologe 2017; 38: 416-421.

21 Gaensbacher S, Waldhoer T, Berzlanovich A. The slow death of autopsies: a retrospective analysis of the autopsy prevalence rate in Austria from 1990 to 2009. Eur J Epidemiol 2012; 27: 577-580.

22 Roberts IS, Benamore RE, Benbow EW, et al. Post-mortem imaging as an alternative to autopsy in the diagnosis of adult deaths: a validation study. Lancet 2012; 379: 136-142. 
23 Tsitsikas DA, Brothwell M, Chin Aleong JA, et al. The attitudes of relatives to autopsy: a misconception. J Clin Pathol 2011; 64: 412-414.

24 Saldana L, Abid M, McCarthy N, et al. Factors affecting delay in initiation of treatment of tuberculosis in the Thames Valley, UK. Public Health 2013; 127: 171-177.

25 Cruz-Ferro E, Ursua-Diaz MI, Taboada-Rodriguez JA, et al. Epidemiology of tuberculosis in Galicia, Spain, 16 years after the launch of the Galician tuberculosis programme. Int J Tuberc Lung Dis 2014; 18: 134-140.

26 Nagu T, Ray R, Munseri P, et al. Tuberculosis among the elderly in Tanzania: disease presentation and initial response to treatment. Int J Tuberc Lung Dis 2017; 21: 1251-1257.

27 Lee CT, Gollamudi SP, Myint KS, et al. Not just atypical presentation, but also atypical site: tuberculosis in elderly adults. J Am Geriatr Soc 2016; 64: e51-e52.

28 Perez-Guzman C, Vargas MH. Mycobacterial infections in the elderly. Semin Respir Crit Care Med 2010; 31 575-586.

29 Waitt CJ, Squire SB. A systematic review of risk factors for death in adults during and after tuberculosis treatment. Int J Tuberc Lung Dis 2011; 15: 871-885.

30 Przybylski G, Dabrowska A, Pilaczynska-Cemel M, et al. Unemployment in TB patients - ten-year observation at regional center of pulmonology in Bydgoszcz, Poland. Med Sci Monit 2014; 20: 2125-2131.

31 Kurbatova EV, Taylor A, Gammino VM, et al. Predictors of poor outcomes among patients treated for multidrug-resistant tuberculosis at DOTS-plus projects. Tuberculosis 2012; 92: 397-403.

32 Lucenko I, Riekstina V, Perevoscikovs J, et al. Treatment outcomes among drug-susceptible tuberculosis patients in Latvia, 2006-2010. Public Health Action 2014; 4: Suppl. 2, S54-S58.

33 Mathew TA, Ovsyanikova TN, Shin SS, et al. Causes of death during tuberculosis treatment in Tomsk Oblast, Russia. Int J Tuberc Lung Dis 2006; 10: 857-863.

34 Nagavci BL, de Gelder R, Martikainen P, et al. Inequalities in tuberculosis mortality: long-term trends in 11 European countries. Int J Tuberc Lung Dis 2016; 20: 574-581.

35 Kolappan C, Subramani R, Kumaraswami V, et al. Excess mortality and risk factors for mortality among a cohort of TB patients from rural south India. Int J Tuberc Lung Dis 2008; 12: 81-86.

36 Borgdorff MW, Veen J, Kalisvaart NA, et al. Mortality among tuberculosis patients in The Netherlands in the period 1993-1995. Eur Respir J 1998; 11: 816-820.

37 Chiang CY, Lee JJ, Yu MC, et al. Tuberculosis outcomes in Taipei: factors associated with treatment interruption for 2 months and death. Int J Tuberc Lung Dis 2009; 13: 105-111.

38 GBD Tuberculosis Collaborators. The global burden of tuberculosis: results from the Global Burden of Disease Study 2015. Lancet Infect Dis 2018; 18: 261-284.

39 Public Health England. Tuberculosis in England: 2018. London, PHE, 2018. 